\title{
Psychosocial sequelae in 29 children with giant congenital melanocytic naevi
}

\author{
H. M. Koot, F. de Waard-van der Spek, * C. D. Peer, ${ }^{*}$ P. G. H. Mulder ${ }^{\dagger}$ and A. P. Oranje* \\ Department of Child and Adolescent Psychiatry, Erasmus University Rotterdam, *Department of Dermato-Venereology, University Hospital Rotterdam and \\ tDepartment of Epidemiology and Statistics, Erasmus University Rotterdam, the Netherlands
}

\begin{abstract}
Summary
Giant congenital melanocytic naevus (GCMN) may be expected to affect psychosocial functioning of children and their parents due to deviant appearance and painful treatment. To obtain insight into clinical aspects and psychosocial functioning of those suffering from GCMN, 29 children diagnosed with GCMN syndrome or single GCMN received a dermatological examination, were interviewed, and their mothers and teachers completed standardized questionnaires on the child's competence and behavioural/ emotional problems and their own adjustment. Social problems were reported for $30 \%$ of the patients and behavioural/emotional problems for $25.9 \%$. There was no correlation between visibility of the naevus, treatment or child age and psychological problems. Mothers reported considerable psychosocial burden. It is concluded that children with GCMN are at increased risk of social and behavioural/emotional problems, and mothers suffer considerable psychological impact of their child's condition.
\end{abstract}

\section{Introduction}

Giant congenital melanocytic naevus (GCMN) is rarely observed in neonates. A GCMN may be single or is accompanied by multiple, diffusely spread satellite naevi in which cases the term GCMN syndrome is used. Complications of GCMN include malignant melanoma development ${ }^{1-7}$ in about $5 \%$ of cases and neurological deficits in 5\% (leptomeningeal melanocytosis, epilepsy, focal neurological symptoms). ${ }^{2,8}$ Naevi overlying the spine can be associated with spina bifida and meningomyelocele ${ }^{2}$. We performed a transversal study in 29 children with GCMN aged 1-18 years to assess psychosocial functioning.

\section{Methods}

\section{Patients}

The medical records of 250 children diagnosed with a

Correspondence: H. Koot, Department of Child and Adolescent Psychiatry, Erasmus University Rotterdam, Dr Molewaterplein 60, 3015 GJ Rotterdam, The Netherlands. Tel.: +31 10 4636671. Fax: +31 104636803.

E-mail: koot@psys.azr.nl

Accepted for publication 7 July 2000 congenital melanocytic naevus at the University Hospital Rotterdam in the past 18 years were examined. To be included in the study the patient's naevi had to meet the following criteria according to Taïeb: ${ }^{8}$ (i) on trunk and limbs the naevi cover $5 \%$ of the body surface or more; (ii) on head and neck the naevi are larger than the patient's palm; (iii) multiple naevi of medium size (diameter $5-10 \mathrm{~cm}$ ) are diffusely distributed all over the body surface (GCMN syndrome).

The above criteria were fulfilled by 44 patients (22 girls and 22 boys). Of this group, 36 families were traced of which 29 (66\%; 16 girls, 13 boys; mean child age 8.7 years, $\mathrm{SD}=4.3$ ) agreed to participate.

Of the 29 families, 19 visited the Paediatric Dermatology Unit for a dermatological examination of the naevus by a dermatologist. History was taken, paying special attention to therapeutical interventions and dermatological changes in the appearance of the naevus or naevi. Patients who could not be examined in the hospital were questioned by telephone and the naevus was studied using a picture. To record the size of the GCMN as objectively as possible it was measured vertically and horizontally using a tape measure and drawn in a standard figure of a boy or girl (Figs 1 and 2 ). The cosmetic result after intervention was measured 
Figure 1 GCMN location in girls.
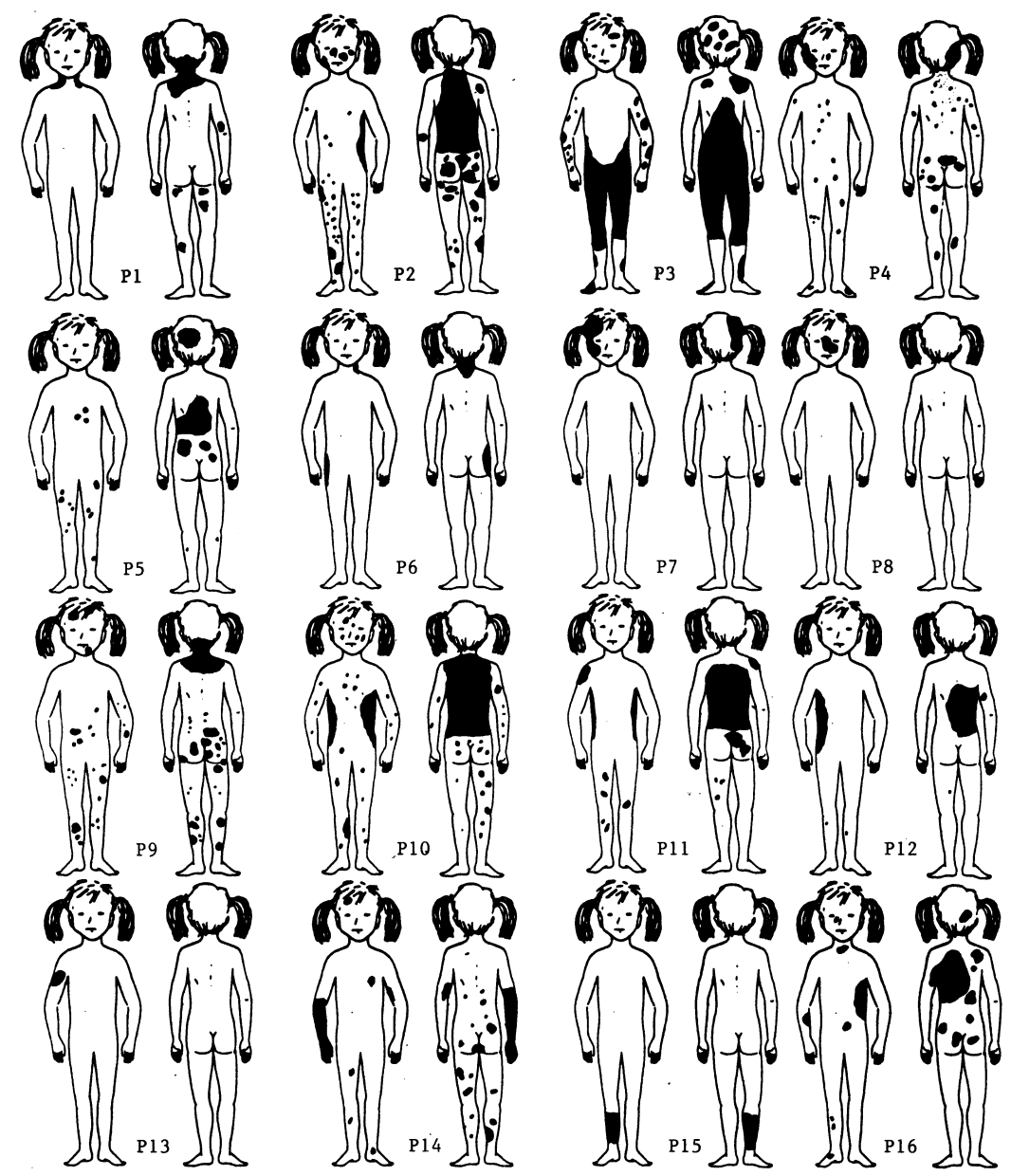

by the satisfaction of the child, the parents and the dermatologist using an interview format designed for this study (one family refused to be interviewed).

\section{Psychosocial aspects}

For children older than 3 years the Child Behaviour Checklist for Ages 4-18 ${ }^{9}$ (CBCL/4-18) and Teacher's Report Form ${ }^{10}$ (TRF) was used to obtain standardized parent ratings of children's competence (24 3- and 4point items) and parent and teacher ratings of children's behavioural/emotional problems (120 items). The reliability and validity of both scales documented by Achenbach $^{9,10}$ were confirmed for the Dutch translation. ${ }^{11-14}$ Both rating scales are scored on an internalizing scale including withdrawn and anxious/ depressed behaviour and somatic complaints, and externalizing scale including delinquent and aggressive behaviour. Further, a total problems and a total competence score are computed.
All mothers completed the 10-item (5-point Likert scale ranging from 0 to 4 , strongly agree to strongly disagree) checklist for Parental Adjustment to Congenital Disorder, ${ }^{15}$ in this case their child having a GCMN. A total adjustment score (Cronbach's $\alpha, 0.89$ ) was computed by summing the first nine item scores.

Data were analysed with binomial tests to compare observed and expected proportions, Pearson correlations to compare parent and teacher reports, and two-tailed Student's $t$-tests to compare means using SPSS for Windows, version 8.0.

\section{Results}

\section{Dermatologic and therapeutic aspects}

Seventeen children (59\%) suffered from a GCMN syndrome and 12 (41\%) from a single GCMN (Figs 1 and 2). In the group with the GCMN syndrome 12 (71\%) were girls and five $(29 \%)$ were boys. In the group 


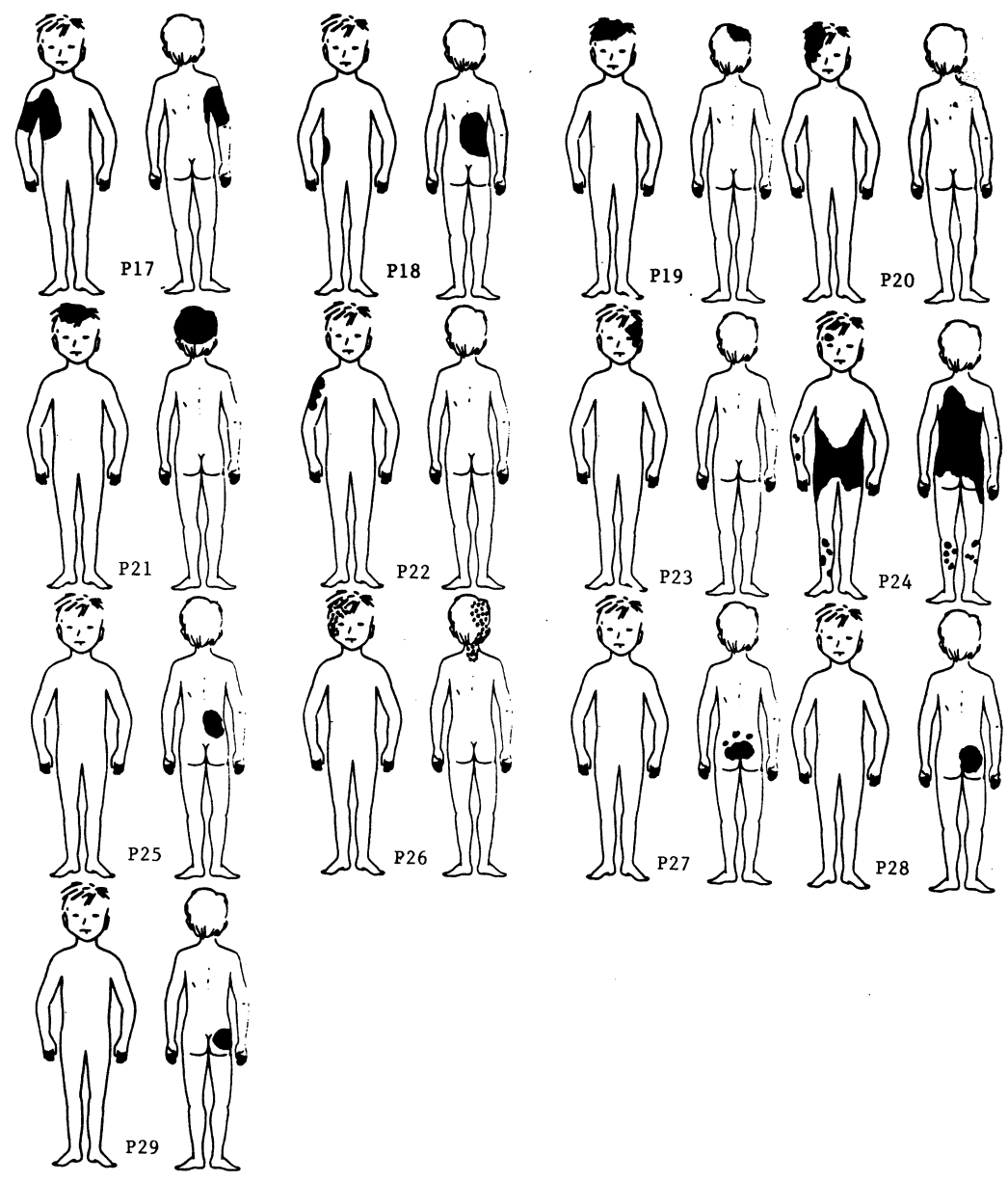

Figure 2 GCMN location in boys.

with a single GCMN eight $(67 \%)$ were boys and four (33\%) were girls.

In none of the cases had malignant transformation occurred. In two cases (7\%) epilepsy was diagnosed (p3 and p28). In only one (p3) this was proven to be related to the GCMN syndrome. The age when the epilepsy presented for the first time was 8 years in p3 and 11 years in $\mathrm{p} 28$.

In three of the cases the GCMN appeared somewhat lighter coloured in comparison to the last control, especially at the edges (p10, p16, p19). None of the children reported functional impediment resulting from the GCMN.

Most cases had undergone therapy for prophylactic antimelanoma reasons (surgery in most cases, dermabrasion or laser treatment). Mean age at the time of the first therapeutic intervention was for the excision technique $(n=17) 3.6$ years, for the dermabrasion $(n=4) 7$ weeks and for the laser technique $(n=3)$ 8.4 years. In two-thirds of cases the doctors, patients and family agreed on the degree of satisfaction with the result of treatment.

\section{Psychosocial aspects}

Neither mean parent ratings nor mean teacher ratings of children's competence and behavioural/emotional problems were significantly different from Dutch normative CBCL/4-18 and TRF scores. However, 30\% of the children were scored by their mothers below the fifth percentile on the CBCL competence scale $(P<0.01)$. Further, of the 27 children for whom the CBCL/4-18 was completed, seven (25.9\%; five girls, two boys) had a total problem score above their age- and sex-based normative cut-point for clinically deviant scores, which is significantly different from the norm-based expectation of $10 \%(P=0.01)$. In all cases problems were of both internalizing and externalizing nature, most obvious anxious/depressed and aggressive behaviour, and social problems. None of the children were scored in the 
Table 1 Maternal adjustment to child congenital anomaly in 29 cases.

\begin{tabular}{|c|c|c|c|}
\hline & Agree (\%) & Neutral (\%) & Disagree (\%) \\
\hline I think it is awful that my child was born with a congenital anomaly & 69.0 & 10.3 & 20.7 \\
\hline I feel that I have adjusted well to my child having a congenital anomaly & 82.8 & 10.3 & 6.9 \\
\hline I feel guilty when I think about my child having a congenital anomaly & 13.8 & 3.4 & 82.8 \\
\hline I feel very unsafe since I know that my child has a congenital anomaly & 10.3 & 13.8 & 75.9 \\
\hline I have accepted well that my child has a congenital anomaly & 58.6 & 20.7 & 20.7 \\
\hline $\begin{array}{l}\text { My sense of self-worth has decreased considerably since I know that my child has a } \\
\text { congenital anomaly }\end{array}$ & 6.9 & 10.3 & 82.8 \\
\hline I blame myself for my child having a congenital anomaly & 6.9 & 6.9 & 86.2 \\
\hline I withdraw from social contacts because my child has a congenital anomaly & 0.0 & 6.9 & 93.1 \\
\hline As a parent of a child having a congenital anomaly I don't feel valuable & 0.0 & 10.3 & 89.7 \\
\hline My life has been enriched by my child having a congenital anomaly & 24.1 & 27.6 & 48.3 \\
\hline
\end{tabular}

deviant range by their teacher. However, correlations between parent and teacher $(n=20)$ problem scores were 0.35 for internalizing, 0.70 for externalizing, and 0.61 for total problems.

To test whether psychological problems were related to visibility of the naevus, treatment or age we compared the mean parent- and teacher-rated problem scores of those whose naevus was highly visible $(n=17)$ vs. those whose naevus was not or only slightly visible $(n=12)$, of those who were operated $(n=18)$ vs. those who were not $(n=11)$, and of younger $(n=15$; ages $\leq 7$ years) vs. older children ( $n=14 ; \geq 8$ years $)$. Although some differences in group means on internalizing, externalizing or 'total problems' scores were fairly large none were statistically significant, due to the large within-group variation. This diversity is, for example, shown by the fact that deviant problem scores were obtained both by children with highly visible naevus (p1, p3, p6, p26) and children with naevus not highly visible (p13, p15, p28).

On the adjustment to 'congenital disorder' questionnaire most mothers $(69.0 \%)$ indicated that they found it awful to have a child born with GCMN, and many of them (41.4\%) thought they had not accepted it (Table 1).

\section{Discussion}

In this series of 29 cases, two children were suffering from epilepsy. This finding supports the need for neurological screening early in life in all children suffering from GCMN. Especially if naevi are located on the scalp, the neck and overlying the spine, the chance of central nervous system involvement is present.

In most cases therapeutic intervention had led to an outcome which was satisfactory to the child, the parents and the doctor. In a few cases, excessive scar formation or return of the pigment in the excised area occurred. After dermabrasion the adverse event observed most often was ongoing hairgrowth. The children themselves were of the opinion that a burnlike scar was far more socially acceptable than having a naevus. The cosmetic results after laser treatment looked promising. However, this treatment was only performed in three cases and is still in an experimental phase. Curettage of the naevus in the first 2-6 weeks of life seem also to be promising, but was not performed in this group of patients. ${ }^{5}$

Some specific psychosocial abnormalities related to the GCMN were detected. Most children were and felt socially handicapped. Thirty percent scored under the fifth percentile on the CBCL competence scales, most notably on social competence. Children tended to avoid situations in which they were required to undress, such as sports and swimming. Further, comparison of problem scores with Dutch norms revealed a 2.5 times higher prevalence of both behavioural and emotional problems in children with GCMN. However, the problems were not related to visibility of the naevi, having been operated or the age of the child. These figures show that having a GCMN may create problems associated with specific social situations which involve public exposure of body parts, as well as an increased risk of behavioural/emotional problems which can reflect on the child's well-being. Similar effects have been noted for other conditions affecting physical appearance, such as cleft lip and palate, spina bifida, or childhood cancer. $^{16-18}$ Perceived physical appearance may have direct and indirect effects on depressive symptoms and social anxiety, with the indirect effects mediated by general self-esteem. ${ }^{18}$ Therefore, for children with GCMN to cope with their deviant appearance, we might try to improve their competence to cope with negative evaluations from peers and adults alike.

Most parents indicated considerable psychosocial burden of having a child with GCMN. Many parents 
became very emotional when talking about the repercussions of the anomaly.

Although parental report using the Parental Adjustment Scale indicated that parents found it awful and hard to accept having a child with GCMN, the vast majority seemed to cope relatively well with this burden.

In conclusion, 29 children with GCMN were studied. Malignant transformation into melanoma was not observed; in a few cases neurological abnormalities related to the GCMN were detected. The increased risk of psychosocial problems in children with GCMN seems to be related mainly to the cosmetic aspects of the condition. Because of the psychosocial repercussions later in life, preventive psychological and cosmetic treatment should be performed early in life.

\section{References}

1 De Mey A, Dupuis C, Lejeune F. Neonatal treatment of giant naevi. Dermatology 1992; 185: 300-1.

2 Hurwitz S. Congenital melanocytic nevi. In: Hurwitz S, ed. Clinical Pediatric Dermatology: a Textbook of Skin Disorders of Childhood and Adolescence. Philadelphia: Saunders, 1993: 203-37.

3 Kuflik JH, Janniger CK. Congenital melanocytic nevi. Cutis 1994; 53: 112-4.

4 Mackie RM. Congenital melanocytic naevi. In: Champion RH, Burton JL, Ebling FJG, eds. Textbook of Dermatology. New York: Blackwell, 1994: 1540-3.

5 De Raeve LE, De Coninck AL, Dierickx PR, Roseeuw DI. Neonatal curretage of giant congenital melanocytic nevi. Arch Dermatol 1996; 132: 20-2.

6 Petres J, Müller RPA. Treatment of congenital pigmented nevi by dermabrasion. In: Happle R, Grosshans E, eds. Pediatric Dermatology. Berlin: Springer, 1987: 135-42.

7 Sandsmark M, Eskeland G, Ogaard AR. Treatment of large congenital naevi. Scan J Plast Reconstr Hand Surg 1993; 27: 223-32.
8 Taïeb A, Maleville J. The giant pigmented naevus. a retrospective multicenter study of 102 cases. In: Happle R, Grosshans E, eds. Pediatric Dermatology. Berlin: Springer, 1987: 127-34.

9 Achenbach TM. Manual for the Child Behavior Checklist and 1991 Profile. Burlington: Department of Psychiatry University of Vermont, 1991.

10 Achenbach TM. Manual for the Teacher's Report Form and 1991 Profile. Burlington: Department of Psychiatry University of Vermont, 1991.

11 Verhulst FC, Akkerhuis GW, Althaus M. Mental health in Dutch children: I A cross-cultural comparison. Acta Psychiatrica Scand 1985; 72 (Suppl.): 323.

12 Verhulst FC, Akkerhuis GW. Mental health in Dutch children: III Behavioural/emotional problems reported by teachers of children aged 4-12. Acta Psychiatrica Scand 1986; 74 (Suppl.): 330.

13 De Groot A, Koot HM, Verhulst FC. Cross-cultural generalizability of the Child Behavior Checklist crossinformant syndromes. Psychol Assess 1994; 6: 225-30.

14 De Groot A, Koot HM, Verhulst FC. Cross-cultural generalizability of the YSR and TRF cross-informant syndromes. J Abnormal Child Psychol 1996; 24: 65164.

15 Bouman NH, Passchier J. Checklist for Parental Adjustment to Child Congenital Anomalies. Rotterdam: Erasmus University, 1995.

16 Richman LC, Millard T. Brief report: Cleft lip and palate: Longitudinal behavior and relationships of cleft conditions to behavior and achievement. J Pediatric Psychol 1997; 22: 487-94.

17 Appleton PL, Minchom PE, Ellis NC, Elliott CE, Böll V, Jones P. The self-concept of young people with spina bifida: a population-based study. Dev Med Child Neurol 1994; 36: $198-215$.

18 Varni JW, Katz ER, Colegrove R, Dolgin M. Perceived physical apperance and adjustment of children with newly diagnosed cancer: a path analytic model. J Behav Med, 1995; 18: 261-78. 